\title{
ESTRATÉGIAS DE COOPERAÇÃO PARA A COMPETITIVIDADE NO SETOR TÊXTIL BRASILEIRO
}

COOPERATION STRATEGIES FOR COMPETITIVENESS IN THE BRAZILIAN TEXTILE SECTOR

ESTRATEGIAS DE COOPERACIÓN PARA LA COMPETITIVIDAD EN EL SECTOR TEXTIL BRASILEÑO

\author{
ADILSON CALDEIRA \\ Doutor \\ Universidade Presbiteriana Mackenzie - Brasil \\ adilson.caldeira@mackenzie.br \\ DIEGO HENRIQUE VIEIRA DURÃO \\ Bacharel \\ Universidade Presbiteriana Mackenzie - Brasil \\ diego.vieira1992@hotmail.com
}

FERNANDA ROSSI PIZZOL Bacharel

Universidade Presbiteriana Mackenzie - Brasil fer_pizzol@hotmail.com

HENRIQUE ROSSI PIZZOL Bacharel

Universidade Presbiteriana Mackenzie - Brasil henrique_pizzol_7@hotmail.com

DAVI WIESEL BRASIL Bacharel Universidade Presbiteriana Mackenzie - Brasil dwbrasil0@gmail.com

Submetido em: 19/05/2015 Aprovado em: 15/09/2015

Doi: alcance.v22n3.p333-348

\section{RESUMO}

O cenário competitivo determinado pelo avanço da globalização desafia as empresas a buscar opções estratégicas de inserção no mercado internacional, não somente para atuação em diferentes países como também para a competitividade local. Como esse desafio é comum a diferentes agentes de um mesmo setor de atividade, a adoção de estratégias de cooperação entre fornecedores, compradores e até mesmo concorrentes pode ser um caminho para o fortalecimento competitivo de todos. Com o propósito de conhecer possíveis contribuições que a cooperação proporciona à competitividade das empresas do setor têxtil na internacionalização de negócios, realizou-se uma pesquisa qualitativa exploratória, envolvendo entrevistas com profissionais que atuam em diferentes segmentos da cadeia produtiva têxtil e análise de documentos e publicações que refletem dados conjunturais. Os dados revelam que a internacionalização ocorre predominantemente via inserção comercial e, em menor escala, por inserção produtiva. Também se evidencia que estratégias cooperativas podem contribuir à internacionalização de empresas do setor face ao potencial de redução de custos, evolução tecnológica e otimização de processos. Apesar do reconhecimento desse potencial em um cenário de competição internacional, contudo, essa cooperação tem se revelado menor do que poderia ser, principalmente devido à resistência a compartilhar informações com concorrentes.

Palavras-Chave: Cooperação. Competitividade. Internacionalização.

Revista Alcance - Eletrônica - vol. 22 - n. 3 - jul./set. 2015 


\section{ABSTRACT}

The competitive landscape determined by the advance of globalization challenges companies to pursue strategic options for insertion in the international market, not only to operate in different countries, but also for local competitiveness. As this is a common challenge to different players in the same sector of activity, the adoption of cooperation strategies between suppliers, customers and even competitors may be means of competitive strengthening of all. Seeking to identify possible contributions that the adoption of cooperative strategies provides for the competitiveness of Brazilian companies in the textile sector, in terms of the internationalization of business, an exploratory qualitative study was carried out involving interviews with professionals operating in different segments of the textile production chain. Documents and publications concerning this industry were also analyzed. The research reveals that internationalization occurs predominantly through trading inclusion and, to a smaller extent, productive insertion. It also shows that cooperative strategies can contribute to the internationalization of companies through potential cost reduction, technological evolution, and optimization of processes. However, despite the potential of operating an international competition scenario, this cooperation has proven to be less extensive than it could be, mainly due to a reluctance to information sharing among direct competitors.

Keywords: Cooperation. Competitiveness. Internationalization.

\section{RESUMEN}

El panorama competitivo determinado por el avance de la globalización desafía a las empresas a buscar alternativas estratégicas de inserción en el mercado internacional, no solamente para la actuación en diferentes países sino también para la competitividad local. Como ese reto es común a diferentes agentes de un mismo sector de actividad, la adopción de estrategias de cooperación entre proveedores, compradores e incluso competidores puede ser un camino para el fortalecimiento competitivo de todos. Con el propósito de conocer los posibles aportes con que la cooperación contribuye a la competitividad de las empresas del sector textil en la internacionalización de negocios, se realizó una investigación cualitativa exploratoria, incluyendo entrevistas con profesionales que actúan en distintos segmentos de la cadena productiva textil y análisis de documentos y publicaciones que reflejan datos coyunturales. Los datos revelan que la internacionalización ocurre predominantemente por la inserción comercial y en menor escala por la inserción productiva. También se hace evidente que las estrategias cooperativas pueden contribuir a la internacionalización de empresas del sector frente a la potencial reducción de costos, evolución tecnológica y optimización de procesos. A pesar del reconocimiento de esa potencialidad en un escenario de competición internacional, esa cooperación se ha revelado menor de lo que podría ser, principalmente debido a la resistencia a compartir informaciones con los concurrentes.

Palabras Clave: Cooperación. Competitividad. Internacionalización.

\section{INTRODUÇÃO}

O século XXI se iniciou em meio a um processo de aceleração dos benefícios que a globalização trouxe aos cidadãos, proporcionando novas aplicações da tecnologia para satisfação de suas necessidades e desejos. Por outro lado, trouxe às empresas o desafio de competir em um novo contexto de concorrência em âmbito internacional (THURROW, 2005).

$\mathrm{O}$ acirramento da concorrência internacional impinge às empresas a necessidade de ações estratégicas para se manterem competitivas, seja por ações individuais ou em parceria com fornecedores, compradores e, até mesmo, competidores. Quando se trata de competir internacionalmente, o próprio governo pode ser parceiro, agenciando condições favoráveis a aspectos como a conquista e mercados ou acesso a novas tecnologias. Essa concepção vai de encontro ao paradigma de que competição é sinônimo de individualismo. Estratégias de cooperação e competição podem ser adotadas de modo simultâneo e complementar, como meio para a conquista de benefícios recíprocos (CASTELLS, 2011).

Um setor em que esse cenário se faz presente é o da indústria têxtil e de confecções brasileiro. Embora importante para o desempenho econômico do Brasil, com expressiva participação no Produto Interno Bruto (PIB) e na geração de empregos do país, já teve desempenho superior em um passado recente. Essa queda se deve 
principalmente à forte concorrência de produtos estrangeiros, principalmente os procedentes de países asiáticos (ABRAMACO, 2015).

O Brasil conta com empresas que atuam em todos os elos da cadeia produtiva têxtil, que vão da produção de fibras ao comércio varejista (ABIT, 2015). Com tal característica, há potencial para uma cooperação entre as empresas dos diferentes elos dessa cadeia para que o setor continue forte no cenário econômico e realize ganhos em competitividade em âmbito local e internacional.

Inspirado por esse quadro contextual, este estudo aborda a contribuição das ações de cooperação para a competitividade do setor têxtil brasileiro no cenário internacional. A discussão se pauta pelo problema de pesquisa expresso na questão: quais contribuições a adoção de estratégias de cooperação proporciona às empresas brasileiras do setor têxtil para a competitividade na internacionalização de negócios?

O objetivo geral é conhecer possíveis contribuições que a cooperação proporciona à competitividade das empresas do setor têxtil na internacionalização de negócios. Para o alcance desse objetivo, estabelecem-se como objetivos específicos: a) analisar as principais formas de internacionalização existentes no mercado; b) conhecer estratégias de cooperação praticadas pelas empresas do setor em busca de competitividade; c) compreender as contribuições de estratégias de cooperação no processo de internacionalização de empresas brasileiras do setor têxtil.

\section{REFERENCIAL TEÓRICO}

\subsection{Estratégias para internacionalização de negócios}

A globalização se caracteriza pela organização das atividades de produção, consumo e circulação de mercadorias e produtos em escala internacional. Castells (2011) sustenta que o fenômeno ocasiona o surgimento de uma rede de conexões, fazendo com que as empresas estejam interligadas desde o processamento de recursos até a produção de bens de consumo.

Almeida (2007) indica a importância da internacionalização ao argumentar que a necessidade de explorar novos mercados é crescente, pois as oportunidades encontradas em alguns países são limitadas, o que comumente resulta em dificuldade de sobrevivência se as operações da empresa se restringirem a seu mercado local. Há, ainda, o fato de que a internacionalização abrange a entrada de empresas estrangeiras para disputar esse mercado local.

Os estudos acadêmicos apresentam diferentes visões sobre o que caracteriza a internacionalização de empresas. Em alguns, o foco se direciona para a atividade específica da empresa, como as considerações de Waters e Rinsler (2014) e Borges (2015) acerca dos desafios da internacionalização da logística e da cadeia de suprimentos no processo de industrialização em cenário global; Meyer et al. (2014), que alertam para os desafios que as empresas de serviços enfrentam para se alinhar a interesses de seus clientes em âmbito internacional; ou Crick, D. e Crick, J. (2014), com a abordagem da natural internacionalização de empresas de alta tecnologia. Em um sentido geral, Mendes (2011) e Cintra e Mourão (2005) entendem que as empresas só se tornam internacionalizadas quando que seus negócios geram movimentação internacional de fatores de produção. Somente a exportação, ou o simples processo de comercialização entre países, não caracterizariam este processo.

A Escola Nórdica de Negócios Internacionais, da universidade sueca de Uppsala, considera que a inserção comercial também é um estágio relevante do processo de internacionalização de empresas, que se dá de forma incremental em etapas (HILAL; HERMAIS, 2003). Com base nessa concepção, conhecida como Modelo de Uppsala, Duarte e Tanure (2006) argumentam que a internacionalização ocorre gradualmente por meio de operações entre agentes econômicos de diferentes países. Mendes (2011), por sua vez, recorre ao Modelo de Upsalla para destacar que o processo de internacionalização ocorre mediante quatro passos: $1^{\circ}$.) manifestação do interesse de realizar negócio com o país alvo, seguido de relações comerciais; $2^{\circ}$.) implementação de processo de exportação via representantes no novo país; $3^{\circ}$.) fixação de subsidiária para promoção de vendas no novo país; $4^{\circ}$.) implantação de unidade de produção.

Ainda de acordo com o Modelo de Upsalla, a internacionalização pode ocorrer via inserção comercial ou inserção produtiva. A primeira se realiza pela exportação, direta (sem intermediários), ou indireta (via agentes, tais como Trading Offices), ou, ainda por meio da criação de cooperativas (MENDES, 2011). A segunda se dá por Investimento Direto Estrangeiro (IDE), em três modalidades (Green Field, com a construção de instalações no novo país, Fusões e Aquisições ou Joint Ventures), ou, ainda por relações contratuais (franquias, licencia- 
mentos e contratos de produção) (DUARTE; TANURE, 2006). A Figura 1 apresenta uma sintese ilustrativa da ramificação desse processo.

Figura 1: Ramificação do processo de internacionalização

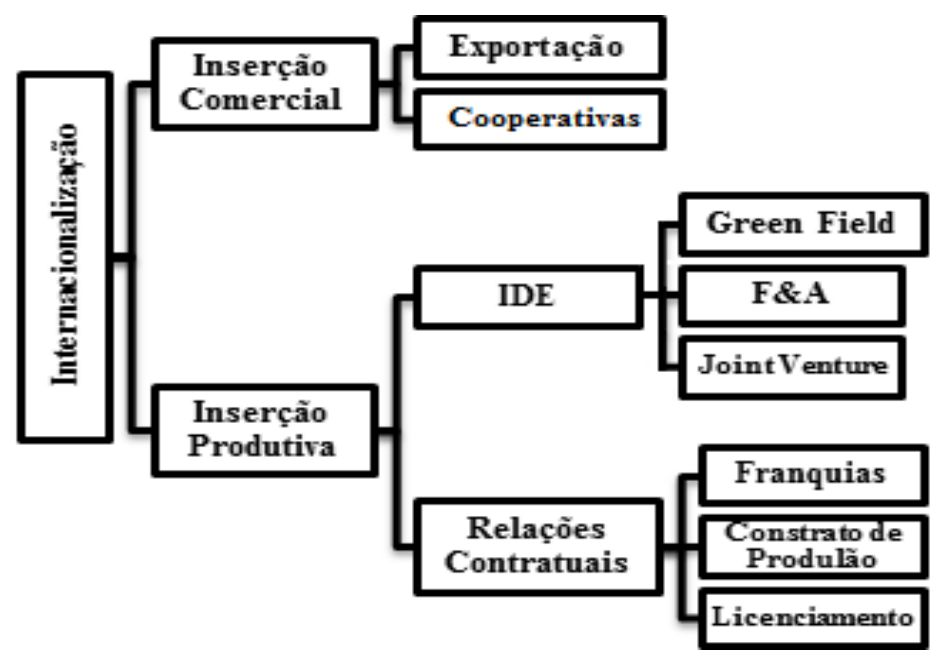

Fonte: Elaborada pelos autores.

Em síntese, as propostas encontradas na literatura apresentam visões que se complementam e refletem diferentes concepções sobre estratégias para a internacionalização de negócios, conforme apresentado na Tabela 1.

Tabela 1: Visões sobre internacionalização

\begin{tabular}{cl}
\hline Fonte & \multicolumn{1}{c}{ Visão } \\
\hline Castells & Interligação de atividades de produção, consumo e circulação em escala global, \\
$(2011)$ & com o surgimento de uma rede de conexões, desde o processamento de recursos \\
& até a produção de bens de consumo. \\
Almeida & O acirramento da concorrência motiva a internacionalização. Limitar-se às oportu- \\
$(2007)$ & nidades locais resulta em dificuldade de sobrevivência, mesmo porque o mercado \\
Cintra e Mourão & local pode ser alvo de empresas estrangeiras. \\
(2011) & ção, que se configura mediante a instalação e a produção. \\
Hilal e Hermais & Segundo o Modelo de Uppsala, a inserção comercial é fator relevante para a inter- \\
(2003) & nacionalização de empresas, mas não suficiente. O processo de internacionaliza- \\
& ção se dá de forma incremental. \\
Mendes & Processo de internacionalização de empresas (Modelo de Uppsala): manifestação \\
(2011) & do interesse de realizar negócio com o país alvo, exportação via representantes, \\
& fixação de subsidiária e implantação de unidade de produção no novo país. \\
Duarte e Tanure & Duas formas de internacionalização: inserção comercial e produtiva. A primeira se \\
(2006) & dá por vias diretas, indiretas ou por cooperação. A segunda, por investimento direto \\
\hline
\end{tabular}

Fonte: Elaborada pelos autores.

\subsection{Estratégias de cooperação para a competitividade}

A década de 1990 caracterizou-se pelo início de uma revolução tecnológica que resultou em um aumento do nível de exigência do mercado, pela própria expectativa do público consumidor quanto ao potencial de benefícios decorrentes de novas tecnologias. Observou-se, assim, um cenário competitivo mais complexo. De acordo com Castells (2011), as empresas passaram a buscar novas capacitações para se manterem e se desta- 
carem no mercado sob as novas condições estabelecidas com a revolução tecnológica. Uma das alternativas foi o estabelecimento de interações e inter-relacionamento visando à cooperação entre empresas com o propósito do desenvolvimento de condições que lhes proporcionasse lograr conjuntamente condições para se adequar às exigências do mercado (MARTINS, 2012).

Olave e Amato Neto (2005) ressaltam que os modelos de gestão baseados na complementaridade, no compartilhamento e na associação entre empresas se mostram como referência inovadora para promover sobrevivência e competitividade no mercado globalizado. Molinari e Winckler (2011) defendem o ideal de que cooperação e colaboração possuem características diferentes. A cooperação representa um conjunto de ações complementares entre os agentes envolvidos, visando aos mesmos resultados, com divisão proporcional dos ganhos. Na colaboração, por outro lado, não há previsão de ganhos para todas as partes envolvidas no processo, pois se trata de um conceito de apoio, beneficiando um elemento em específico na forma de auxílio.

Encontram-se, na literatura, relatos de experiências que envolvem colaboração entre agentes de diferentes setores de atividade, em geral motivadas por interesses comuns. Ainda que sejam concorrentes, algumas empresas podem ser favorecidas conjuntamente quando se unem para conquistar competitividade para seu setor territorial ou regional, conforme abordam estudos como o de Celata e Coletti (2014). Outros exemplos são parcerias para a conquista de ganhos em aspectos tecnológicos, como ilustram trabalhos como os de Verschoore et al. (2014) e Da Costa e Porto (2014). Ou seja, por motivos variados, competidores optam por cooperar em prol de interesses competitivos comuns.

Dentre os paradoxos que abordam a importância da interação entre os agentes no mercado para a construção conjunta de condições competitivas favoráveis, a Teoria dos Jogos propõe, segundo Fiani (2009), vários insights para estimular o desenvolvimento do pensamento estratégico nos negócios, a fim de auxiliar a tomada decisão e estruturar o pensamento competitivo. O principal alicerce desta teoria consiste no exercício de se colocar na posição do parceiro ou do concorrente, e raciocinar sobre quais seriam os passos a serem seguidos nas situações propostas, modelando as interações e avaliando os pontos positivos e negativos para a formulação de uma ação estratégica eficiente.

Martins (2012) afirma que a Teoria dos Jogos parte do pressuposto que a necessidade de obter vantagens no mercado é uma prioridade para qualquer elemento. Contudo, visar somente aos interesses individuais promove maior possibilidade de riscos, que podem gerar resultados negativos. Deste modo, fica evidente a necessidade de dividir responsabilidades e riscos, diminuindo as incertezas, com o objetivo de potencializar a obtenção de resultados positivos.

Nesse contexto, abre-se espaço para a discussão sobre a conveniência das empresas em adotar estratégias simultaneamente competitivas e cooperativas. Em uma das visões sobre essa proposta, emergiu o termo "coopetição", um neologismo construído a partir da ideia de fusão dos ideais de cooperação e competição. Em linhas gerais, essa concepção considera que as empresas devem cooperar entre si para atingir um determinado objetivo previamente estabelecido, mas devem competir na hora de dividir os ganhos. Na prática, essa teoria estabelece um jogo de negócios entre os agentes externos, que formam uma Rede de Valores. Deste modo, as empresas inseridas na Rede de Valores, estando mais próximas de fornecedores, clientes e concorrentes, podem se aproveitar dos benefícios promovidos dentro dessa relação (NALEBUFF; BRANDENBURGER, 1996).

Para Nalebuff e Branderburger (1996), não é sempre que o ambiente corporativo se assemelha a um campo de batalha, em que se necessita derrotar a concorrência, capturar cotas de mercado e pregar-se aos consumidores. Podem ocorrer situações em que o sucesso de uma empresa é diretamente proporcional ao de outras. Como exemplo, os autores citam o caso em que a demanda de mercado por processadores da marca Intel aumentou quando a Microsoft criou programas mais poderosos que requerem processadores adequados para executá-los. Ou seja, a estratégia competitiva de uma empresa pode favorecer outra em um mesmo mercado.

Ao se referir à evolução dos conceitos sobre negociação, Martinelli (2002) sugere que a relação ganhaganha, em que ambas as partes envolvidas têm seus interesses atendidos, seria a situação ideal. Trata-se de um raciocínio análogo ao da coopetição, em que se busca estabelecer uma relação em que todas as partes envolvidas nas estratégias de negócios têm suas exigências e interesses devidamente atendidos.

A Tabela 2 apresenta uma síntese das principais visões sobre a questão da cooperação para a competitividade abordada na literatura que pautou este estudo. 
Tabela 2: Síntese das visões sobre estratégias de cooperação para a competitividade

\begin{tabular}{|c|c|}
\hline Fonte & Visão \\
\hline $\begin{array}{l}\text { Castells } \\
(2011)\end{array}$ & $\begin{array}{l}\text { Acirramento da concorrência amplia a dificuldade de sobrevivência e competitividade, } \\
\text { quebrando paradigmas e proporcionando oportunidade a inovadores modelos de ges- } \\
\text { tão, que abordam o papel dos concorrentes, clientes e fornecedores como parceiros. }\end{array}$ \\
\hline $\begin{array}{l}\text { Porter } \\
\text { (2011) }\end{array}$ & $\begin{array}{l}\text { Estratégias de posicionamento competitivo no setor a partir da defesa de cinco elemen- } \\
\text { tos básicos: rivalidade entre concorrentes ameaça novos entrantes, ameaças de produ- } \\
\text { tos substitutos, poder de negociação perante fornecedores e poder de negociação com } \\
\text { clientes. }\end{array}$ \\
\hline $\begin{array}{l}\text { Martins } \\
(2011)\end{array}$ & $\begin{array}{l}\text { O aumento dos níveis de exigência do mercado fez com que as empresas passassem a } \\
\text { buscar novas ferramentas para sobreviver e se destacar sob as novas condições impos- } \\
\text { tas a partir da revolução tecnológica. Uma das ferramentas utilizadas como alternativa } \\
\text { foi o estabelecimento de interações e inter-relações mediante a cooperação entre em- } \\
\text { presas. }\end{array}$ \\
\hline $\begin{array}{l}\text { Martinelli } \\
\text { (2009) }\end{array}$ & $\begin{array}{l}\text { A evolução de diferentes conceitos colaborou para a caracterização do conceito de } \\
\text { negociação como uma relação ganha-ganha, em que todas as partes envolvidas têm } \\
\text { seus interesses atendidos. }\end{array}$ \\
\hline $\begin{array}{l}\text { Fiani } \\
(2009)\end{array}$ & $\begin{array}{l}\text { Segundo a Teoria dos Jogos, o pensamento competitivo deve ser realizado de forma } \\
\text { estratégica, analisando os impactos das próprias decisões e prevendo os impactos das } \\
\text { decisões de terceiros. }\end{array}$ \\
\hline $\begin{array}{c}\text { Mollinari e Winckler } \\
\text { (2011) }\end{array}$ & $\begin{array}{l}\text { Cooperação e colaboração com diferentes significados: cooperação é um conjunto de } \\
\text { ações complementares entre os agentes envolvidos, com objetivo de atingirem os } \\
\text { mesmos resultados e dividirem os ganhos; na colaboração não há previsão de ganhos } \\
\text { para todas as partes envolvidas no processo, mas apenas uma forma de auxílio, em } \\
\text { benefício de um elemento específico. }\end{array}$ \\
\hline $\begin{array}{l}\text { Nalebuff e Branden- } \\
\text { burger } \\
(1996)\end{array}$ & $\begin{array}{l}\text { A coopetição é o fenômeno que ocorre por meio da cooperação entre empresas, respei- } \\
\text { tando os aspectos de competição. Em linhas gerais, significa que as empresas devem } \\
\text { cooperar entre si para atingir um determinado objetivo previamente estabelecido, mas } \\
\text { devem competir na hora de dividir os ganhos. }\end{array}$ \\
\hline $\begin{array}{l}\text { Olave e Amato } \\
\quad(2005)\end{array}$ & $\begin{array}{l}\text { Os modelos de gestão baseados na complementaridade, no compartilhamento e na } \\
\text { associação entre empresas se mostram como uma referência inovadora para promover } \\
\text { sobrevivência e competitividade no mercado globalizado. }\end{array}$ \\
\hline
\end{tabular}

Fonte: Elaborada pelos autores.

\section{DESAFIOS COMPETITIVOS E INTERNACIONALIZAÇÃO NO SETOR TÊXTIL BRASILEIRO}

O setor têxtil, um dos mais importantes da economia nacional, foi responsável por 1,6 milhões de pessoas empregadas e por um faturamento de $\mathrm{R} \$ 130,2$ bilhões em 2014 , significativa fatia de $12,3 \%$ do Produto Interno Bruto (PIB). No entanto, o setor já participou, no passado, de $37 \%$ do PIB brasileiro. Um dos aspectos indicados como causadores dessa queda é o assédio da concorrência internacional, principalmente de produtos asiáticos (ABRAMACO, 2015).

Esses dados representam o desempenho de participantes de todos os elos da cadeia produtiva têxtil brasileira, abrangendo desde a produção e beneficiamento de tecidos até a confecção de produtos acabados, destinados ao consumo, conforme ilustra a Figura 2. Ali se observa que as matérias-primas básicas da cadeia produtiva são as fibras naturais, sintéticas ou artificiais. Esse segmento, segundo SEBRAE (2000), é intensivo em capital e no Brasil conta com grandes empresas. Nas mais eficientes e de maior porte os fios brasileiros são competitivos, ao passo que nas de médio porte a produção encontra grande concorrência global.

A fiação possui papel fundamental na cadeia produtiva têxtil, processando as fibras e transformando-as nos fios que alimentam os elos seguintes, em que figuram a tecelagem ou a malharia. Na tecelagem existem basicamente três linhas importantes de tecidos, que são classificados em: a) tecidos pesados; b) tecido de cami- 
saria e c) tecidos para cama, mesa, banho e decoração. Neste elo encontra-se uma commodity, que são os tecidos pesados, produtos básicos e com padrões definidos, assim apresentando um mercado com competição acirrada entre os países, o que acaba exigindo qualidade, preço e alta escala de produção para garantir competitividade (SEBRAE, 2000).

No outro elo em que o produto da fiação é utilizado, a malharia é responsável pela produção de outra commodity, que são as camisetas $t$-shirts, artigos de moletom e malhas de náilon com elastano para produção de roupas íntimas, entre outros produtos. Este é um segmento em que há a possibilidade de empresas de pequeno e médio porte operarem, pois exige menores investimentos de capital do que o segmento de tecelagem.

Figura 2: Configuração básica da cadeia produtiva têxtil e de confecção

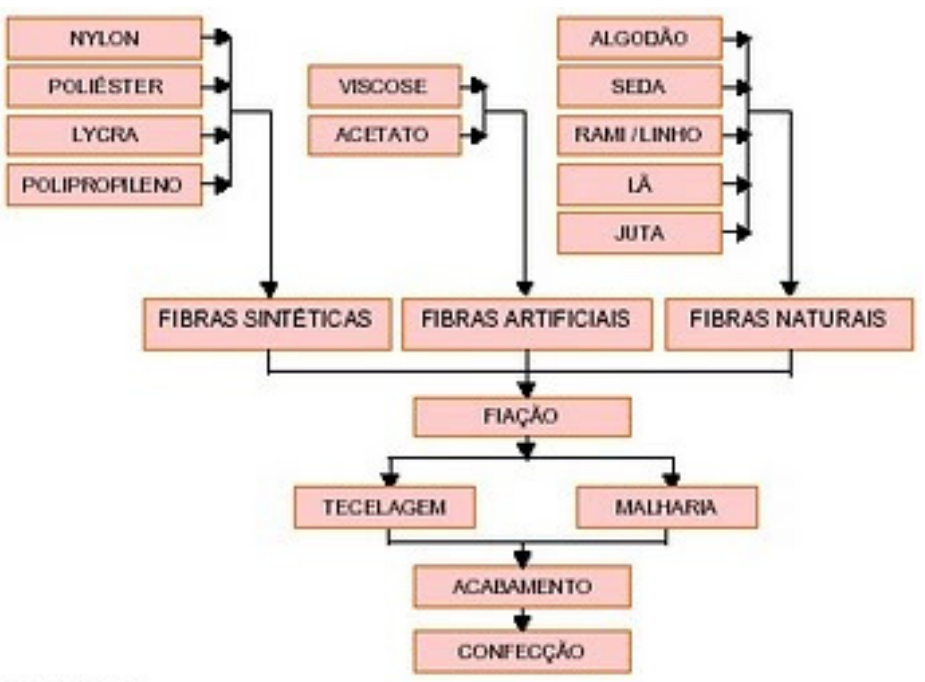

Fonte: SEBRAE (2000).

O acabamento consiste em um conjunto de operações que trarão aos produtos propriedades especificas, tais como aparência, conforto e durabilidade. Na ponta final da cadeia encontra-se o elo da confecção, um segmento heterogêneo, contando com mais de 20 ramos distintos, sendo que a grande concentração está no ramo de vestuário (SEBRAE, 2000).

Bragaglia (2012) destaca que os resultados do setor têxtil brasileiro têm sido comprometidos principalmente pelo acirramento da concorrência com as empresas estrangeiras, além de aspectos como a carga tributária e elevados custos locais de produção. A situação se evidencia em exemplos como o do maior polo têxtil do país, localizado em Americana, no interior do Estado de São Paulo, que há alguns anos era responsável por $80 \%$ do Produto Interno Bruto (PIB) do município e atualmente responde por somente $25 \%$. Atribui-se essa queda de desempenho à concorrência de produtos procedentes da China, que dominou o mercado brasileiro, e à diminuição do consumo de produtos têxteis em países da Europa e nos Estados Unidos em decorrência de crises econômicas.

A Agência Brasileira de Promoção de Exportações e Investimentos (Apex-Brasil), em conjunto com a Associação Brasileira da Indústria Têxtil e de Confecções (ABIT), lançou, em 2000, o programa denominado Texbrasil. Com o objetivo de tornar as empresas brasileiras referências internacionais em inovação, design e sustentabilidade, o programa estimula e facilita a participação em feiras e eventos ao redor do mundo e presta serviço de agendamento de visitas a possíveis compradores e jornalistas de outros países, o que também gera a possibilidade de realização de pesquisas e prospecções no mercado externo (TEXBRASIL, 2015).

Essa preocupação com a cooperação em busca de competitividade e com os benefícios esperados de iniciativas para a internacionalização dos negócios remete a um questionamento sobre qual é a visão que os empresários e os gestores de empresas que atuam em diferentes elos da cadeia possuem e quais ações promovem em busca de resultados nesse sentido. Promoveu-se, assim, uma pesquisa empírica com esse propósito, descrita nos tópicos seguintes. 


\section{PROCEDIMENTOS METODOLÓGICOS}

Optou-se por seguir o método qualitativo de pesquisa, que parte do princípio de que os pressupostos assumidos são passíveis de observação, mas sem possibilidade de serem medidos. Essa escolha pauta-se na recomendação de Richardson (2011), de que a abordagem qualitativa na pesquisa é o meio mais adequado para compreender a natureza de um fenômeno, descrever a importância de um problema, verificar a interação de determinadas variáveis ou até mesmo compreender fatos vivenciados por grupos sociais.

O estudo possui fim exploratório, pois se trata de pesquisa cujo objetivo é conhecer as razões do caso que está sendo investigado, composto por um tema atual que ainda pode vir a ser explorado, conforme comenta Richardson (2011).

Como estratégia de pesquisa, recorreu-se a dados primários e secundários. Os secundários foram obtidos em publicações relativas ao setor estudado e documentos cedidos por associações representativas de classe desse setor. Para a coleta de dados primários, recorreu-se a entrevistas em profundidade com gestores de empresas que atuam na cadeia produtiva têxtil, bem como pessoas com vivência no desenvolvimento de estratégias de cooperação com outras empresas para a internacionalização, com o intuito de ganho de vantagem competitiva no mercado.

A Tabela 3 apresenta a qualificação e o elo cadeia produtiva têxtil em que os sujeitos de pesquisa possuem experiência.

Tabela 3: Caracterização dos entrevistados

\begin{tabular}{|c|c|c|}
\hline $\begin{array}{l}\text { Entre- } \\
\text { vistado }\end{array}$ & Qualificação & Elo da Cadeia Têxtil \\
\hline E1 & $\begin{array}{l}\text { Professor Universitário em curso de Administração } \\
\text { Ex-Professor de Curso Têxtil } \\
\text { Ex-Consultor de empresas no setor têxtil } \\
\text { Ex-Empresário e Diretor de Empresa Têxtil }\end{array}$ & $\begin{array}{l}\text { Consultoria de implementação de projetos } \\
\text { Indústria de produção de tecidos (tecela- } \\
\text { gem) }\end{array}$ \\
\hline E2 & $\begin{array}{l}\text { Assessor em empresa de importação e exporta- } \\
\text { ção de tecidos }\end{array}$ & Importação e Exportação de tecidos \\
\hline E3 & $\begin{array}{l}\text { Proprietário de microempresa de importação de } \\
\text { tecidos chineses }\end{array}$ & Importação de tecidos chineses \\
\hline E4 & Proprietário de loja de roupas & $\begin{array}{l}\text { Confecção/Varejo de roupas voltado para } \\
\text { classe C e D }\end{array}$ \\
\hline E5 & Proprietário de microempresa de malharia & Malharia/Produção de artigos para vestuário \\
\hline E6 & Coordenador de relacionamento & $\begin{array}{l}\text { Consultoria de capacitação da indústria } \\
\text { têxtil para internacionaliza- } \\
\text { ção/Associação de classe do setor têxtil }\end{array}$ \\
\hline
\end{tabular}

Fonte: Elaborada pelos autores.

Para a coleta de dados, optou-se pela realização de entrevistas em profundidade, utilizando-se um roteiro pré-elaborado com 10 perguntas abertas formuladas a partir do modelo conceitual construído por meio da pesquisa bibliográfica, e destacando os principais aspectos descritos na síntese elaborada nas tabelas 1 e 2 , apresentadas anteriormente na seção 2 deste texto.

Os dados foram interpretados segundo o modelo de Bardin (2010), destinado à análise de conteúdo. Primeiramente foi realizada a pré-análise dos principais pontos obtidos nas entrevistas de leitura superficial, tendo assim o primeiro contato com o material. Seguido da elaboração de uma tabela de frequências quanto ao surgimento de palavras para a identificação dos núcleos de comunicação, assim reagrupando-os em classes alinhadas ao foco da pesquisa. Finalmente, foi recolhido o conteúdo das entrevistas em observações que auxiliaram a resposta dos objetivos gerais e específicos da pesquisa. 
Conforme propõe Bardin (2010), a divisão do conteúdo em categorias facilita a análise, uma vez que possibilita 0 agrupamento de assuntos comuns entre si. Deste modo foram criadas quatro categorias, a partir das unidades de significado, que servem como ponte para essas categorias, e pontos chaves em que foram identificadas palavras e expressões chaves diretamente relacionadas com o problema e os objetivos da pesquisa. As categorias, as unidades de significado e os pontos chaves estão relacionados na Tabela 4.

Tabela 4: Categorias de análise

\begin{tabular}{|c|c|c|}
\hline Categorias & Unidades de Significado & Pontos-Chave \\
\hline $\begin{array}{l}\text { C1: Aspectos favoráveis e } \\
\text { desfavoráveis à coopera- } \\
\text { ção entre empresas }\end{array}$ & $\begin{array}{l}\text { US1: Desunião no setor } \\
\text { US2: Mentalidade dos em- } \\
\text { presários sobre praticas de } \\
\text { cooperação } \\
\text { US3: Mentalidade dos em- } \\
\text { presários sobre o conceito de } \\
\text { cooperação }\end{array}$ & $\begin{array}{l}\text { Desconfiança dos empresários } \\
\text { Não ver concorrente como nocível parceiro } \\
\text { Medo de compartilhar } \\
\text { Conservadorismo dos empresários e dos gestores } \\
\text { Receio de compartilhar informações internas } \\
\text { Possibilidade de agregar valor } \\
\text { Redução de custos ao setor }\end{array}$ \\
\hline $\begin{array}{l}\text { C2: Pontos positivos e } \\
\text { negativos do produto brasi- } \\
\text { leiro referentes à competiti- } \\
\text { vidade }\end{array}$ & $\begin{array}{l}\text { US4: Qualidade do produto } \\
\text { US5: Questões tributárias } \\
\text { US6: Eficiência da produção }\end{array}$ & $\begin{array}{l}\text { Falta de investimento em inovação e tecnologia } \\
\text { Relação Qualidade X Custo } \\
\text { Alta carga tributária incidente no setor têxtil } \\
\text { Máquinas obsoletas } \\
\text { Falta de investimento na produção brasileira }\end{array}$ \\
\hline $\begin{array}{l}\text { C3: Forte concorrência no } \\
\text { mercado interno devido a } \\
\text { produtos estrangeiros }\end{array}$ & $\begin{array}{l}\text { US7: Influência da China } \\
\text { no comércio internacional } \\
\text { US8: Globalização da } \\
\text { produção }\end{array}$ & $\begin{array}{l}\text { Baixo custo da mão de obra chinesa } \\
\text { Custo país } \\
\text { Incentivos governamentais } \\
\text { Características dos produtos } \\
\text { Falta de competitividade em custos em relação ao } \\
\text { produto chinês. }\end{array}$ \\
\hline $\begin{array}{l}\text { C4: Pouca participação do } \\
\text { Brasil no mercado interna- } \\
\text { cional e incentivos à expor- } \\
\text { tação }\end{array}$ & $\begin{array}{l}\text { US9: Programas de esti- } \\
\text { mulo à exportação no } \\
\text { setor têxtil brasileiro. } \\
\text { US10: Representativi- } \\
\text { dade das exportações } \\
\text { brasileiras } \\
\text { US11: Mentalidade para a } \\
\text { exportação }\end{array}$ & $\begin{array}{l}\text { Estudos para a identificação de mercados poten- } \\
\text { ciais } \\
\text { Investimento na qualificação do empresário } \\
\text { Condicionantes de competitividade } \\
\text { Alta carga tributária incidente no setor têxtil } \\
\text { Cultura imediatista para exportação } \\
\text { Oportunismo econômico } \\
\text { Falta de conhecimento }\end{array}$ \\
\hline
\end{tabular}

Fonte: Elaborada pelos autores.

\section{APRESENTAÇÃO E ANÁLISE DOS DADOS}

A Categoria 1 - Aspectos favoráveis e desfavoráveis à cooperação entre empresas remete ao fato de que a abordagem de estratégias de cooperação em busca de ganhos conjuntos se mostra uma alternativa para que as empresas encontrem meios para sobreviver aos desafios que surgiram com o avanço da globalização, conforme argumenta Castells (2011). Uma das alternativas propostas para isso é a coopetição proposta por Nalebuff e Brandergurguer (1996). Entretanto, no setor têxtil brasileiro, essa prática não acontece com frequência, conforme entendem alguns entrevistados:

[...] isso não é uma coisa muito comum. As empresas do setor não costumam cooperar. [...] a nossa empresa não tem cooperação com outras empresas têxteis, fora os nossos fornecedores $[\ldots](E-2)$.

[...] existe uma competição gigantesca. As indústrias procuram se fortalecer mais com tecnologia, pesquisa e tudo que é possivel para produzir melhor, com o menor custo [...]. O melhor possivel para minar o seu concorrente. Então, não há a menor possibilidade de uma cooperação (E-4). 
Ao explicarem as diretrizes da coopetição, Nalebuff e Branderburger (1996) se balizam em analogias referentes aos paradigmas no mundo empresarial. Uma delas é a comparação do ambiente competitivo corporativo a um campo de batalha, em que o empresário deve rechaçar seu concorrente a qualquer custo. É comum que alguns empresários enfrentem barreiras e dificuldades semelhantes, pois nem sempre se é capaz de perceber que o sucesso de uma empresa está diretamente relacionado ao sucesso de outra. São ilustrações:

[...] 0 brasileiro não acredita na Cooperação como fator positivo para a competitividade. 0 brasileiro vê o seu concorrente como o seu arquiinimigo. (E-2)

[...] $O$ pessoal têxtil é muito desconfiado, muito conservador. (E-1)

[...] Aqui não, normalmente 0 empresário ou o negociante que está do outro lado, olha pra você querendo te tirar da frente. Se ele puder te tirar da frente para ele somar, ter a somatória da lucratividade dele, ele faz. (E-3)

As entrevistas revelam que, na maioria dos casos, o empresário não se dispõe a parcerias por não estar interessado em apresentar informações de sua empresa, devido a uma relação não amigável com o concorrente. Deste modo, é difícil ocorrer a negociação ganha-ganha, proposta por Martinelli (2002), que é um dos principais alicerces do conceito de coopetição.

[...] aquela história do conservadorismo e da desconfiança do empresário brasileiro. Ele não quer que o concorrente saiba o quanto ele produz (E-1).

[...] As empresas, aqui do Brasil, elas são muito desunidas, existe muita desconfiança: "não vou abrir todos os meus problemas para o meu concorrente, para o meu parceiro, não quero abrir meus custos" (E-6).

Para Molinari e Winckler (2011), a coopetição está baseada em interações entre atores que vivenciam um conflito, em que sentimentos de rivalidade e cooperação podem surgir de modo aleatório e simultâneo no decorrer dessa relação. $O$ surgimento de conflitos dessa natureza dificulta o cenário de coopetição. Esta premissa se evidencia no fato de se considerar o empresário brasileiro desconfiado, e caracteriza o setor têxtil como um setor desunido. As entrevistas revelam que a coopetição já foi tentada como alternativa, mas sem sucesso, diante das características inerentes à mentalidade dos empresários do setor:

[...] quando eu trabalhei em um projeto do SEBRAE, eu insisti nisso e senti que o pessoal tinha aversão a isso. Eu lembro que uma vez foi um empresário lá, e ficou cheio de ironia comigo porque eu propus isso. Tem empresa que produz muito tecido. Você pega todo esse tecido, junta e coloca num beneficiamento, ou monta uma beneficiadora para atender todas as empresas, o pessoal tem aversão (E-1).

Ainda que predomine, entre os empresários do setor, receio e aversão pela ideia da coopetição, vários entrevistados, quando questionados sobre a importância e os benefícios que a adoção de estratégias cooperativas poderia trazer, apontaram a premissa de que a coopetição no setor seria capaz de promover redução de custos, aumentar a qualidade do produto ofertado e agregar valor. Este raciocínio se evidencia nas seguintes falas:

[...] se você fizesse a cooperação entre empresas do setor, traria redução de custo, um poderia fornecer para 0 outro $[\ldots](\mathrm{E}-1)$.

[...] primeiro, o aparelhamento tecnológico. Nós teríamos que, tecnologicamente, estar preparados para competir de igual para igual com outros países. Para isso nós voltamos nas questões burocráticas. O Brasil poderia facilitar questões burocráticas de importação, redução de impostos e carga tributária [...] (E-3).

[...] não é só o agregar valor ao produto. [...] Quando a empresa entende o mercado internacional e começa a ajustar a gestão dela aqui no Brasil, os próprios colaboradores vão entender [...] eu não acho que é só o ganho de agregar valor, mas é de ter uma mudança cultural muito grande. (E-4). 
Apesar da coopetição não ser prática comum no setor têxtil brasileiro, o raciocínio exposto pelos empresários converge com Olave e Amato Neto (2005), para quem os modelos de gestão balizados na complementaridade, no compartilhamento e na associação são uma referência inovadora para promover sobrevivência e competitividade no mercado globalizado.

$\mathrm{Na}$ Categoria 2 - Pontos positivos e negativos do produto brasileiro referentes à competitividade, é possível perceber que as principais barreiras enfrentadas estão diretamente ligadas a questões econômicas e governamentais. $O$ grau de competitividade dos produtos chineses e a alta carga tributária que o governo brasileiro atribui ao setor são destacados em trechos como os seguintes:

Tem barreiras alfandegárias, por exemplo, eles botam impostos que são bem grandes. $0 \mathrm{im}$ posto de importação de roupas bate no GATT, ele encosta no GATT, ele só não passa do GATT porque não pode, porque se pudesse, ele passaria (E-2).

O Estado não está muito interessado em apoiar empresários, ele está interessado em saber qual a margem de contribuição que o empresário vai dar para ele no primeiro dia útil do mês seguinte. Isso é nocivo, é profundamente nocivo, isso é anti-desenvolvimentista (E-3).

[...] por que comprar lá fora? Se mesmo com todos os encargos, chega a pagar quase $100 \%$ do produto da China que chega no Brasil. O produto chega com 100\% a mais de impostos e continua mais barato do que o que a gente produz aqui (E-4).

O pensamento proposto pelos entrevistados confirma que o momento é de apreensão quanto à perda de espaço no mercado interno, conforme evidenciam a redução da produtividade e 0 aumento das importações. O montante elevado de tributos incidentes no setor influencia, de maneira negativa, a produção. A consequência para as empresas brasileiras diante dessa situação foi a perda de competitividade, devido à incapacidade de inovar, conforme afirma um dos entrevistados:

O que acontece é que o produto brasileiro não é competitivo porque as máquinas são obsoletas. Então, qual é o problema? As máquinas. [...] Ela é bastante cara porque está carregada de imposto e nunca houve incentivo do governo no sentido de acabar com o imposto. Tinha uma maneira de contornar isso no sentido de incentivos fiscais. [...] E como você paga isso? Repassa para o preço do produto (E-1).

A alternativa encontrada para lidar com a falta de competitividade dos produtos brasileiros, ocasionada pelo alto volume de impostos, foi importar materiais e produtos acabados de outros países, principalmente da China, o que se revela na seguinte opinião:

[...] é muito difícil você concorrer com a China porque a China leva a máquina a muito menor preço e pagava um salário muito baixo para os operários [...] e eles têm uma política fiscal que é diferente do Brasil [...] o custo Brasil? É isso. Esse monte de impostos (E-1).

Seguindo a mesma linha de Bragaglia (2012), que apresenta a situação do setor têxtil brasileiro como preocupante, os profissionais atuantes no setor criticam a postura no governo por não atuar de maneira eficiente na diminuição das barreiras existentes e na criação de incentivos, como se observa nos trechos a seguir:

Eu posso te dizer quem não é um parceiro, o Governo não é um parceiro (E-2).

O Brasil tem muitas possibilidades, um país gigantesco desse teria condições de ter produtos com preço competitivo, para concorrer com a China, se tivéssemos políticas mais voltadas para uma questão tributária ou coisa parecida (E-4).

Quando questionados sobre as principais fontes de competição da indústria têxtil, os empresários persistiram na ideia de que, no cenário brasileiro, o preço é o principal elemento a ser considerado para a obtenção de bons resultados, uma vez que o produto brasileiro possui qualidade para competir com os demais países, mas seu preço é alto em relação à concorrência, devido aos encargos tributários. Esta questão é evidente nos seguintes trechos:

[...] preço é tudo, tudo é uma questão de preço. Se produzir aqui no Brasil com bom preço, se você tiver volume, preço e qualidade, você entra em qualquer país. (E-1) 
[...] a qualidade é importante! Só que hoje em dia, as pessoas não aceitam mais uma qualidade tão ruim de produto. Então o que acaba sendo o diferencial: preço. (E-2)

[...] então já que nós temos toda essa dificuldade de custos vai fazer coisas que sejam boas. Então o Brasil produz um excelente tecido e a indústria procura fazer coisas com qualidade. (E-4)

Uma alternativa de sobrevivência da indústria diante das limitações e das dificuldades apresentadas, proposta pelos próprios entrevistados, seria a especialização em um determinado foco de mercado, combinada a ações de marketing eficientes. Deste modo, o setor têxtil é capaz de agregar valor à marca e, consequentemente, aperfeiçoar seus resultados. Este conceito fica evidente nos ideais propostos por um dos entrevistados, quando questionado sobre os possíveis benefícios de concentrar a indústria brasileira em mercados específicos.

[...] Olha o tecido que faz a calça Marca d'água e o tecido que faz a calça Diesel. É praticamente o mesmo, os insumos são os mesmos. E o que faz o cara pagar mil reais em uma calça Diesel e cinquenta reais por uma calça Marca d'água? [...] Você tem a marca, tem valor agregado, o acabamento, o toque. Ou seja, existe uma série de fatores que agregam valor e com isso você consegue ter mercado e permite que essas marcas sejam globais. Por que 0 Brasil não tem mais marcas globais? Diesel é uma marca global, tem muito investimento em marketing. (E-1)

$\mathrm{Na}$ Categoria 3 - Forte concorrência no mercado interno devido a produtos estrangeiros, destaca-se o que afirma Almeida (2007) que, ao se considerar o atual cenário da economia internacional, por meio da globalização integrando diversas nações, alguns setores vêm-se motivando a iniciar um processo de internacionalização devido ao acirramento da concorrência. As entrevistas revelam que um dos principais players a obter eficiência atuando sob esta ótica é a China, que identificou excelentes oportunidades a partir do momento em que os Estados Unidos passaram a utilizar o parque industrial chinês como alternativa:

[...] a América foi usar o parque industrial lá, para despoluir o seu. A China captou todo aquilo, percebeu, começou a produzir para si e começou a exportar para o mundo. [...] então produziam pra América. [...] aproveitaram também e começaram: se a gente produz pra América, vamos ver quais mais países tem? Então vieram para o Brasil com uma mão-deobra muito barata que derrubaram os coreanos (E-3).

Os produtos chineses abalam a concorrência no setor têxtil devido aos baixos custos de mão de obra, aos investimentos em inovação e à eficiência do governo chinês em apresentar estratégias de comércio internacional. 0 impacto disso é evidente na afirmação:

[...] muitas empresas que eram têxteis, começaram a importar. [...] algumas deixaram de ser indústria e passaram a importadoras. [...] parte do pessoal que reclama do produto chinês, está começando a vender o produto chinês. Isso não vale só para têxtil, se você pegar essas grandes empresas de eletrodomésticos: Arno, Philips Walita e vê da onde vêm esses produtos, vem tudo da China! (E-1)

No Brasil, um dos aspectos que oportunizaram a entrada dos produtos chineses foram os impostos, que tornavam a importação uma alternativa economicamente mais viável do que a produção. Este fato fortaleceu a competitividade do produto chinês:

[...] eles têm uma política fiscal que é diferente do Brasil. [...] Então a China ficou competitiva e produz uma quantidade muito grande (E-1).

[...] Por que comprar lá fora? Mesmo com todos os encargos, chega a pagar quase $100 \%$ do produto da China que chega ao Brasil, o produto chega com $100 \%$ a mais de impostos e continua mais barato do que o que a gente produz aqui (E-4).

É importante ressaltar que a competitividade do produto chinês no setor têxtil não está somente ligada ao custo. Em entrevistas com os empresários foi evidenciado que a competitividade dos produtos chineses foi 
aumentando proporcionalmente aos investimentos realizados para atender as necessidades dos mercados alvos. Exemplos deste raciocínio podem ser evidenciados na afirmação:

Aqui, por uma época, houve um bloqueio cultural, trazia-se pouco tecido tingido da China porque as cores da moda de lá, na época, não eram necessariamente as cores da moda aqui. Então começaram a trazer tecido cru e a dar cor aqui. [...] 0 pessoal começou a ir para lá e eles começaram a tingir da cor que o Brasil queria. (E-1)

$\mathrm{Na}$ Categoria 4 - Pouca participação do Brasil no mercado internacional e incentiva à exportação, constata-se que as entrevistas confirmam os ideais propostos no referencial teórico por Hilal e Hermais (2003) que, apoiando-se no Modelo de Uppsala, definiram que a inserção comercial de uma empresa em outras nações também é considerada internacionalização. Conforme descrito no referencial teórico, a ABIT (2013) delimita que um dos principais elementos de apoio à exportação voltado ao segmento têxtil surgiu por meio da própria associação de classe, principalmente no que tange à inserção comercial. Este elemento de apoio é verificado no Programa Texbrasil.

[...] Texbrasil é um programa de internacionalização da indústria da moda brasileira. Quando a gente fala em moda, a gente fala em produto, a gente fala em agregar 0 valor ao produto, nós falamos em marcas, nós falamos em imagem, em vender a imagem tanto da marca, como do Brasil lá fora. (E-6)

Esta passagem se alinha com as fontes bibliográficas, no momento em que o objetivo principal do Programa Texbrasil é definido como uma ferramenta de fortalecimento das empresas da indústria têxtil brasileira. A ABIT (2015) afirma que o Programa Texbrasil busca otimizar a referência de empresas brasileiras ao redor do globo. Como ilustração, pode-se mencionar a seguinte ideia:

[...] o principal objetivo do Texbrasil é capacitar e promover a indústria da moda brasileira. Então, o empresário que não está capacitado, a gente capacita. A gente ensina algumas noções de comércio exterior e de produto. A gente identifica os principais mercados que esses produtos e essas empresas podem atuar. Ou seja, a gente pega o produto que essa empresa fabrica e faz uma análise desse NCM, que é a Nomenclatura Comum do Mercosul, e com esse NCM a gente identifica quais os países que essa empresa seria mais competitiva (E-6).

A necessidade de apoio para a exportação de produtos têxteis brasileiros se mostra importante devido à perda de competitividade do setor nos últimos anos. Como ilustração deste aspecto, há afirmações referentes à representatividade do produto brasileiro no exterior, tais como:

[...] o Brasil perdeu muito mercado, o Brasil deixou de ser uma referência para suprimento de produtos no segmento têxtil para o mundo. Você vê China, você vê Índia, você vê Ásia de um modo geral, liderando isso [...] (E-5)

[...] muito baixo, muito baixo (a representatividade do produto brasileiro no exterior) [...] para vocês terem ideia, o mundo comprou no ano passado, 25 milhões de dólares, o Brasil tem $0,1 \%$ dessa participação, no segmento de lingerie. (E-6)

Retomar representatividade no mercado internacional é uma tarefa complexa e demorada. Deste modo, é necessário que haja um plano de ação eficiente, alinhado a uma estratégia sustentável de médio e longo prazo, conforme afirmam Duarte e Tanure (2006), ao definir a internacionalização como um processo gradual entre agentes econômicos, baseado na troca de experiências e aprendizagens. Essa ideia é comentada na afirmação:

[...], a empresa tem que ter uma decisão estratégica, um plano de médio e longo prazo. Enquanto a empresa não tiver com plano de médio e longo prazo e só exportar por oportunidade ou oportunismo, ela não vai ter sucesso. [...] Hoje o empresário brasileiro é muito imediatista. Quando ele resolve se inserir no mercado internacional, é porque ele entendeu agora que o dólar, com o preço que está, vai ser mais competitivo, [...] vai vender por mais barato e assim vai ter sucesso. (E-6)

Além de revelar a opinião de que os empresários brasileiros passam por um processo de despertar a consciência para os benefícios decorrentes da internacionalização dos negócios, há, segundo ilustra o trecho a

Revista Alcance - Eletrônica - vol. 22 - n. 3 - jul./set. 2015 
seguir, mencionado por um dos entrevistados, o reconhecimento da condição proposta por Martins (2011), de que $o$ aumento dos níveis de exigência do mercado fez com que as empresas passassem a buscar novas ferramentas para sobreviverem e se destacarem sob as novas condições competitivas.

[...] Internacionalização é igual à competitividade mais excelência. [...] aqui, se você atrasa o pedido, não tem para entregar, vai entregar daqui uma semana, o cara vai aceitar. [...] Alguns países não têm isso, se o cara atrasar um dia, ele vai ligar cancelando o pedido [...]. Quando o empresário começa a atuar no mercado internacional, ele começa a ter essa visão de mundo (E-6).

Ou seja, encontra-se, na visão dos entrevistados, uma preocupação com a redução das limitações com que as empresas brasileiras encaram a oportunidade de atuar em âmbito internacional, deixando de considerá-la apenas por um prisma imediatista, objetivando se aproveitar de aspectos econômicos e resultados de curto prazo.

\section{CONSIDERAÇÕES FINAIS}

Pautado pelo objetivo de conhecer possíveis contribuições que a cooperação proporciona à competitividade das empresas do setor têxtil na internacionalização de negócios, este estudo revela que as iniciativas para adoção de estratégias de cooperação entre concorrentes com o objetivo de obtenção de ganhos conjuntos não são comuns. Diante de questões de caráter cultural, os gestores que atuam no setor resistem à aproximação com seus pares, embora reconheçam o potencial de ganhos conjuntos que poderiam resultar dessa estratégia. É do conhecimento dos participantes da pesquisa que já houve tentativas, no passado, para a adoção deste modelo, a fim de otimizar os resultados do setor. Porém, foram frustradas.

Os principais fatores que justificam a ineficiência da adoção do modelo cooperativo residem na mentalidade de profissionais do setor. Os empresários e gestores que nele atuam seguem uma linha conservadora e admitem que a competitividade do setor poderia ser favorecida se enxergassem seus concorrentes como possíveis parceiros. Mas entendem que há riscos que não devem correr, como abrir informações relativas à sua empresa, em especial no que se refere a custos, fornecedores, tecnologia e processos, a seus competidores diretos, nem mesmo via cooperação com agentes que atuam em outros elos da cadeia produtiva.

Apesar da ineficiência na prática da coopetição, os entrevistados reconhecem a importância deste modelo de gestão e acreditam que, caso acontecesse, traria contribuições estratégicas ao setor, proporcionando redução de custos, reforma tecnológica e otimização de processos. Vale ressaltar que a linha de pensamento conservadora dos empresários pode ser justificada pelas dificuldades impostas pelo governo no setor pautado em questão. A alta carga tributária eleva os custos do produto brasileiro e, para se manterem competitivas, as empresas são obrigadas a diminuir a sua margem de lucro, o que colabora ainda mais para que o empresário não se mostre disposto a adotar possíveis estratégias de parceria com seus concorrentes.

O produto brasileiro é considerado de bom nível de qualidade e, no que tange a este quesito, capaz de concorrer diretamente com qualquer outro país. Contudo, os participantes desta pesquisa mencionam a dificuldade de acesso a melhorias tecnológicas no processo produtivo, uma vez que as máquinas são predominantemente importadas e carregadas de impostos. Esse aspecto é indicado como um obstáculo à competitividade, principalmente considerando que as empresas chinesas, que são, atualmente, as principais concorrentes, recebem incentivos fiscais do governo de seu país. Associada ao baixo custo de mão de obra, tal condição fez com que os produtos asiáticos ganhassem grande parcela de mercado ao redor do globo, principalmente no Brasil. Em síntese, apesar de estar capacitada a produzir com qualidade, a indústria têxtil brasileira está em desvantagem competitiva quanto ao custo de produção, o que se reflete, consequentemente, nos preços, comparados aos dos produtos estrangeiros.

O aumento da representatividade de produtos importados é uma preocupação dos órgãos representativos do setor, tais como a ABIT, os quais buscam meios para recuperar a participação do produto têxtil não somente no mercado interno, mas também no mercado externo. Dentre as ações para que isso seja colocado em prática, podem ser citados os programas de incentivo à exportação, promovidos em parceria com o governo brasileiro.

O principal cenário que se encaixa ao conceito proposto é o programa Texbrasil, destinado a fomentar 0 processo de internacionalização de empresas via inserção comercial. O programa, como um elemento de apoio 
à exportação, busca capacitar as empresas brasileiras e promover a indústria da moda no exterior. Para isso, é necessário proporcionar-lhes aprendizagem sobre técnicas de comércio exterior e fazer uma avaliação de mercado do portfólio de produtos da empresa em questão, para identificar quais os mercados que a empresa se tornaria mais competitiva.

Há expectativa dos gestores que participaram desta pesquisa quanto à efetividade de iniciativas, como esse programa na aceleração do processo de internacionalização das empresas brasileiras do setor, mas seu entendimento é de que há a necessidade de mudanças culturais no que se refere ao caráter imediatista atualmente observado. Em busca de resultados rápidos, em muitas ocasiões, exporta-se apenas para aproveitar oportunidades momentâneas, tais como a alta do dólar. Contudo, conforme se constata na literatura especializada, o processo de internacionalização requer um plano estratégico de médio e longo prazo, em que se considerem os riscos e as responsabilidades, para que o produto se insira em novos mercados consumidores, com 0 respaldo da marca Brasil.

A pesquisa revela a existência de condições inibidoras à prática de cooperação entre empresas concorrentes para a obtenção de competitividade na internacionalização de empresas brasileiras do setor têxtil. Devese, porém, reconhecer que as mesmas se referem à visão dos entrevistados e não podem ser consideradas extensivas ao setor têxtil, embora revelem uma tendência a ser verificada em pesquisas complementares mais abrangentes.

É notório que as empresas do setor têxtil brasileiro enfrentam o desafio de desenvolverem competências para a competitividade em âmbito internacional. Portanto, recomenda-se que outros estudos da mesma natureza sejam realizados e que se busque incorporar ao conhecimento sobre esse tema as ações realizadas no setor em referência para lidar com tal desafio.

\section{REFERÊNCIAS}

ABIT. Site institucional da Associação Brasileira da Indústria Têxtil. Disponível em: <http://www.abit.org.br>. Acesso em: 24 fev. 2015.

ABRAMACO. Site institucional da Associação Brasileira de Máquinas e Equipamentos para Confecção. Disponível em: <http://www.abramaco.org.br/publico/noticia.php?codigo=1129>. Acesso em: 24 fev. 2015.

ALMEIDA, A. (Org.) Internacionalização de Empresas Brasileiras Perspectivas e Riscos. Rio de Janeiro: Elsevier, 2007.

BARDIN, L. Análise de conteúdo. Lisboa: Edições 70, 2010.

BORGES, M. A.V. An evaluation of supply chain management in a global perspective. Independent Journal of Management \& Production, v. 6, n. 1, p. 001-029, 2015.

BRAGAGLIA, L. Maior pólo têxtil do Brasil sofre com a concorrência dos chineses. O Estado de São Paulo, São Paulo, 15 de jan. 2012. Disponível em: <http://economia.estadao.com.br/noticias/economia,maior-polo-textildo-brasil-sofre-com-a-concorrencia-dos-chineses,99446,0.htm>. Acesso em: 22 out. 2013.

CASTELLS, M. Sociedade em rede. São Paulo, 2011.

CELATA, F.; COLETTI, R. Place-based strategies or territorial cooperation? Regional development in transnational perspective in Italy. Local Economy, v. 29, n. 4-5, p. 394-411, 2014.

CINTRA, R.; MOURÃO, B. Perspectivas e Estratégias na Internacionalização de Empresas Brasileiras. Revista Autor, São Paulo, Ano 5, n. 53, 2005.

CRICK, D.; CRICK, J. The internationalization strategies of rapidly internationalizing high-tech UK SMEs: Planned and unplanned activities. European Business Review, v. 26, n. 5, p. 421-448, 2014.

DA COSTA, P. R.; PORTO, G. S. Elementos Tecnológicos Determinantes das Capacidades Dinâmicas de Inovação e Cooperação: Um Estudo com as Multinacionais Brasileiras. Iberoamerican Journal of Strategic Management (IJSM), v. 13, n. 3, p. 77-93, 2014.

DUARTE, R. G.; TANURE, B. (Org.). Gestão internacional. São Paulo: Saraiva, 2006.

FIANI, R. Teoria dos Jogos. 3. ed. São Paulo: Elsevier, 2009. 
IEMI. Instituto de Estudos e Marketing Industrial. Disponível em: <http://www.iemi.com.br/biblioteca/publicacoessetoriais/brasil-textil-2013/>. Acesso em: 13 jun. 2014

HILAL, A.; HEMAIS, C. A. O Processo de Internacionalização na Ótica da Escola Nórdica Evidências Empíricas em Empresas Brasileiras. RAC, Curitiba, v. 7, n. 1, p. 109-124, 2003.

MARTINELLI, D. P. Negociação Estratégica: Enfoque sistêmico e visão estratégica. 1. ed. São Paulo: Manole, 2002.

MARTINS, M. F. Cooperação e competitividade numa rede de empresas em Campina Grande-PB: Os desafios para consolidar uma marca com conceito sustentável. Qualitas Revista eletrônica. 1. ed. 2012

MEYER, C. et al. Customer Interaction Uncertainty, Knowledge, and Service Firm Internationalization Strategies. In: Academy of Management Proceedings. Academy of Management, 2014. p. 16861.

MENDES, Z.; FERREIRA, G. Negócios Internacionais e suas aplicações no Brasil. São Paulo: Almedina, 2011.

MOLINARI, G. T.; WINCKLER N. C. Competição, Colaboração, Cooperação, e Coopetição: Revendo conceitos em estratégias interorganizacionais. Revista ADMpg Gestão Estratégica, Ponta Grossa, v. 4, n. 1, p. 145-150, jan./dez. 2011.

NALEBUFF, B.J.; BRANDENBURGER, A.M. Co-opetição. Rio de Janeiro: Rocco, 1996.

OLAVE, M.E.L.; AMATO NETO, J. A formação de redes de cooperação e clusters em países emergentes: uma alternativa para PMEs no Brasil. In: AMATO NETO, João. Rede entre organizações: domínio do conhecimento e da eficácia operacional. São Paulo: Atlas, 2005.

PORTER, M. E. Estratégia Competitiva: Técnicas para análise de indústrias e da concorrência. 7. ed. Rio de Janeiro: Campus, 1997.

RICHARDSON, R. J. Pesquisa social: métodos e técnicas. São Paulo: Atlas, 2011.

SEBRAE. Análise da eficiência econômica e da competitividade da cadeia têxtil brasileira/IEL, CNA e SEBRAE. - Brasília, D.F.: IEL, 2000.

TEXBRASIL. Site Institucional da Texbrasil Programa de Internacionalização da Indústria da Moda Brasileira. Disponível em: <http://www.texbrasil.com.br/texbrasil/index.aspx>. Acesso em: 22 mar. 2015.

THURROW, L. Em defesa da globalização. Revista EXAME, 2005. Disponível em: <http://exame.abril.com.br/revista-exame/edicoes/0834/noticias/em-defesa-da-globalizacao-m0051467>. Acesso em: 07 set. 2013.

VERSCHOORE, J. et al. Concepções teóricas e verificações empíricas sobre a cooperação entre firmas no Brasil: uma introdução ao fórum alianças estratégicas e redes de alianças. RAM. Revista de Administração Mackenzie, v. 15, n. 3, p. 14-20, 2014.

WATERS, D.; RINSLER, S. Global logistics: New directions in supply chain management. Kogan Page Publishers, 2014. 